\title{
Crescimento de plantas de rúcula em substratos e níveis de salinidade da água de irrigação
}

Mirandy dos Santos Dias ${ }^{1}$, Ligia Sampaio Reis ${ }^{2}$, Rilbson Henrique Silva dos Santos ${ }^{2}$, Camila Alexandre Cavalcante de Almeida ${ }^{2}$, Reinaldo de Alencar Paes², Abel Washingthon de Albuquerque ${ }^{2}$, Francisco de Assis da Silva ${ }^{1}$

${ }^{1}$ Universidade Federal de Campina Grande - UFCG, Programa de Pós-graduação em Engenharia Agrícola (Irrigação e Drenagem), Campina Grande, PB. ${ }^{2}$ Universidade Federal de Alagoas - UFAL, Centro de Ciências Agrarias(CECA), Rio Largo, AL. E-mail: mirandydias@gmail.com

\section{Resumo}

O uso de água salina na produção de hortaliças é um dos principais desafios dos produtores, visto que o estresse salino causa diminuição na produção e rendimento das culturas. Objetivou-se avaliar o crescimento de plantas de rúcula em substratos e níveis de salinidade da água de irrigação. O experimento foi conduzido em casa de vegetação, utilizando o delineamento inteiramente casualizado em arranjo fatorial $3 \times 5$ e com quatro repetições. Os tratamentos consistiram de três substratos (solo; húmus de minhoca + areia + solo e torta de filtro + areia + solo) e cinco níveis de condutividade elétrica $(0,5,1,5,2,5$, 3,5 e 4,5 $\mathrm{dS} \mathrm{m}^{-1}$ ). Foram avaliadas as características: altura de plantas, número de folhas, área foliar, massa fresca e massa seca da parte aérea. A interação entre os níveis de salinidade e os substratos testadas não foi significativa para o número de folhas. Níveis crescentes de salinidade da água de irrigação, resulta na redução das características de crescimento de plantas de rúcula cultivar Apreciatta, no entanto, os substratos com adição de matéria orgânica atenuaram os efeitos nocivos da salinidade, sendo uma alternativa viável para o cultivo de plantas de rúcula em condições de salinidade.

Palavras-chave: Eruca sativa; condutividade elétrica; estresse salino.

\section{Growth of arugula plants in substrates and levels of salinity in irrigation water}

\section{Abstract}

The use of saline water in the production of vegetables is one of the main challenges of the producers, since the salt stress causes a decrease in the production and yield of crops. The aim of this study was to evaluate the growth of arugula plants in substrates and salinity levels of irrigation water. The experiment was carried out in a conducted in a greenhouse, using a completely randomized design in factorial arrangement $3 \times 5$ with four replications. The treatments consisted of three substrates (soil; earthworm hummus + sand + soil and filter cake + sand + soil) and five different levels of electrical conductivity (0.5, $1.5,2.5,3.5$ and $4.5 \mathrm{dS} \mathrm{m}^{-1}$ ). The following growth characteristics: plant height, number of leaves, leaf area, fresh weight, and dry weight of shoot. The interaction between the levels of salinity and the substrates tested was not significant for the number of leaves. Increasing levels of irrigation water salinity, result in reduced growth characteristics of Apreciatta cultivar arugula plants, however, substrates with added organic matter attenuated the harmful effects of salinity, being a viable alternative for the cultivation of arugula plants in conditions of salinity.

Key words: Eruca sativa; electrical conductivity; saline stress.

\section{Introdução}

A rúcula (Eruca sativa) é uma hortaliça folhosa, pertencente à família Brassicaceae, de rápido crescimento vegetativo e ciclo curto, de grande aceitação mundial. No Brasil sua produção e consumo são destacados nas regiões Sul, Sudeste e Nordeste, gerando emprego e 
renda à agricultura familiar (GRANGEIRO et al., 2011).

O cultivo desta hortaliça é realizado principalmente por médios e pequenos produtores, que, na maioria das vezes, utilizam águas de fontes superficiais ou de poços rasos, que podem apresentar elevadas concentrações de sais (OLIVEIRA et al., 2012). Para que as plantas alcancem seu máximo desenvolvimento é de grande importância um conjunto de fatores bióticos e abióticos, dentre estes fatores, pode-se destacar o suprimento nutricional e o fornecimento hídrico em quantidade e qualidade satisfatória (SILVA et al., 2008).

O uso de água salina na irrigação tem sido um desafio para produtores rurais $e$ pesquisadores, que constantemente desenvolvem estudos para possibilitar o uso de água de qualidade inferior sem afetar a produtividade das culturas (NASCIMENTO et al., 2015). Para utilização da água de qualidade inferior na agricultura, deve-se utilizar um manejo racional, através de alternativas economicamente viáveis, de modo que a cultura desenvolva a produtividade esperada (MEDEIROS et al., 2007).

A utilização de água com expressivo teor de sais é um dos maiores fatores abióticos que ocasiona efeito negativo no desenvolvimento das plantas, consequentemente diminuindo a produção e rendimento de culturas (JAMES et al. 2012; MUNNS; GILLIHAM, 2015; PLAZEK et al. 2013). Constituindo sério agravante em áreas irrigadas (HASANUZZAMAN et al., 2014).

$\mathrm{Na}$ literatura são encontrados alguns trabalhos sobre o efeito da irrigação com água salina no cultivo da rúcula. No qual a salinidade diminuiu as características de crescimento avaliadas (OLIVEIRA et al., 2012; SILVA et al. 2013; SANTOS et al., 2018).

Uma alternativa utilizada para minimizar os efeitos dos sais sobre o solo e as plantas, é o uso de matéria orgânica no solo, estimulando a redução do potencial osmótico, contribuindo para a absorção de água e, atenuando o dano provocado pela salinização às plantas (DINIZ NETO et al., 2014; FREIRE et al., 2015). No entanto, ainda são escassos trabalhos com ênfase no uso de matéria orgânica como atenuante da salinidade, evidenciando assim a necessidade de pesquisas que resultem em tecnologias viáveis para os produtores; e que possam minimizar os efeitos nocivos do excesso de sais nas plantas, já que é quase obrigatória, em regiões semiáridas, a utilização de águas salinas na agricultura (FREIRE et al., 2016). Diante do exposto, objetivou-se avaliar o crescimento da cultura da rúcula em substratos e níveis de salinidade na água de irrigação.

\section{Material e Métodos}

O experimento foi conduzido no Centro de Ciências Agrárias da Universidade Federal de Alagoas (CECA-UFAL), em condições de casa de vegetação, localizada na latitude de $9^{\circ} 27^{\prime} 55^{\prime \prime} \mathrm{S}$ e longitude de $35^{\circ} 49^{\prime} 46^{\prime \prime} \mathrm{W}$, com uma altitude média de 127 metros acima do nível do mar e temperaturas médias máxima de $29{ }^{\circ} \mathrm{C}$ e mínima de $21^{\circ} \mathrm{C}$. A pluviosidade média anual de 1.800 $\mathrm{mm}$ (SOUZA et al., 2004).

Antes do transplantio, foi realizada a análise química do solo, cujo resultado foi: $\mathrm{pH}=$ 5,$1 ; \mathrm{P}=38 \mathrm{mg} \mathrm{dm}^{-3} ; \mathrm{K}^{2+}=103 \mathrm{mg} \mathrm{dm}^{-3} ; \mathrm{Na}^{2+}=36$ $\mathrm{mg} \mathrm{dm}{ }^{-3} ; \mathrm{Ca}^{2+}=10 \mathrm{cmol} \mathrm{dm}{ }^{-3} ; \mathrm{Mg}^{2+}=0,9 \mathrm{cmol}$ $\mathrm{dm}^{-3} ; \mathrm{Al}^{3+}=0,41 \mathrm{cmol} \mathrm{dm}^{-3} ; \mathrm{H}+\mathrm{Al}=7,3 \mathrm{cmol} \mathrm{dm}$ 3; $\mathrm{SB}=2,3 \mathrm{cmol} \mathrm{dm}^{-3} ; \mathrm{CTC}=9,62 \mathrm{cmol} \mathrm{dm}^{-3} ; \mathrm{V}=$ $24,1 \% ; m=15 \%$; e $M . O=3,21 \%$. Para correção da acidez do solo foi utilizado o calcário agrícola FILLER, com poder relativo de neutralização total (PRNT) de 90\%, mediante a aplicação de $6 \mathrm{~g}$ de $\mathrm{CaCO}_{3}$ por vaso, visando elevar a saturação por bases para $80 \%$ valor recomendado pelo Instituto Agronômico de Campinas (IAC) para a cultura da rúcula (TRANI et al., 2014).

Para os substratos foram realizadas as análises de $\mathrm{pH}$ e condutividade elétrica na EMBRAPA Tabuleiros Costeiros, localizada no município de Rio Largo, AL. As amostras foram determinadas após o preparo dos substratos, mediante a uma relação $1: 2,5$, ou seja, $10 \mathrm{~g}$ de solo para $25 \mathrm{~mL}$ de água destilada. Os valores da determinação de $\mathrm{pH}$ e CE dos substratos estão na Tabela 1.

Tabela 1. Condutividade elétrica e pH dos substratos utilizados no experimento.

\begin{tabular}{ccccc}
\hline Substratos & Becker $(\mathrm{g})$ & Peso Amostra $(\mathrm{g})$ & $\mathrm{pH}$ & CEes $\left.(\mathrm{dS} \mathrm{m})^{-1}\right)$ \\
\hline SUB1 & 34,60 & 10,00 & 7,13 & 1,70 \\
SUB2 & 33,29 & 10,00 & 7,40 & 1,73 \\
SUB3 & 32,35 & 10,00 & 5,94 & 1,61 \\
\hline
\end{tabular}

SUB1- solo da camada de 0-20 cm; SUB2- húmus de minhoca + areia + solo; SUB3- torta de filtro + areia + solo 
0 delineamento adotado foi 0 inteiramente casualizado, em arranjo fatorial $3 \mathrm{x}$ 5 com quatro repetições, sendo cada unidade experimental formada por um vaso contendo uma planta, totalizando 60 unidades experimentais. Os tratamentos consistiram de três substratos (SUB1- solo da camada de 0-20 $\mathrm{cm}$; SUB2- húmus de minhoca + areia + solo; SUB3- torta de filtro + areia + solo), misturados na proporção 2:1:1 e cinco níveis de condutividade elétrica $(0,5,1,5,2,5,3,5$ e 4,5 dS $\left.\mathrm{m}^{-1}\right)$.

Para a produção de mudas de rúculas foram utilizadas sementes da cultivar Apreciatta Folha Larga, cuja germinação se inicia entre 7 a 10 dias. As sementes foram semeadas no dia 08 de maio de 2018 em bandejas de polipropileno expandida, com capacidade para 128 células contendo substrato comercial próprio para produção de mudas. Aos 12 dias após a semeadura (DAS), foi realizado o transplantio para os vasos contendo $2,0 \mathrm{dm}^{3}$ de substrato, correspondente a cada tratamento, deixando uma planta por vaso.

Foi elevada a umidade dos substratos ao nível correspondente a capacidade de campo; para isto, foram pesados quatro vasos de cada tratamento contendo os substratos, saturaram-se os substratos com água, envolvendo os vasos individualmente com plástico, de forma a forçar a perda de água apenas por drenagem (GERVÁSIO et al., 2000). Cessada a drenagem (após dois dias) retiraram-se os plásticos, e logo após os vasos foram pesados em balança eletrônica modelo 3400 (três casas decimais), obtendo-se a média de cada tratamento, correspondente ao nível da capacidade de campo (peso- controle SUB1 $=457$ $\mathrm{mL}$; SUB2 $=294 \mathrm{~mL}$ e SUB3= $632 \mathrm{~mL}$ de água).

Adotou-se um fator de lixiviação igual a zero onde, diariamente, dois vasos de cada tratamento eram pesados, obtendo-se a média desses valores e retornando-se, então, ao pesocontrole com as respectivas soluções. A cada quinze dias corrigiu-se 0 peso-controle (acréscimo de $100 \mathrm{~g}$ ) para compensar o desenvolvimento da planta. Antes de preparar as soluções salinas, as concentrações foram transformadas de $\mathrm{dS} \mathrm{m}^{-1}$ para $\mathrm{g} \mathrm{L}^{-1}$, utilizando a fórmula: $\operatorname{TSD}\left(\mathrm{g} \mathrm{L}^{-1}\right)=0,640 \times \mathrm{CEa}$, em que: $\mathrm{TSD}=$ totais de sais dissolvidos e $\mathrm{CEa}=$ condutividade elétrica da água, obtendo-se assim as concentrações descritas. O preparo das soluções foi feito com o $\mathrm{NaCl}$ e água destilada.

Foi realizada a colheita aos 40 dias após o transplantio (DAT) e avaliado: número de folhas $(\mathrm{NF})$, altura de plantas (AP- $\mathrm{cm}$ ), área foliar (AF$\mathrm{cm}^{2}$ ), massa seca da parte aérea (MSPA- g) e massa fresca da parte aérea (MFPA- g) por planta. Para obtenção da matéria fresca da parte aérea as plantas foram pesadas em balança de precisão (0,01 g).

Após a pesagem as amostras foram colocadas em sacos de papel, identificadas e levadas para secar em estufa com circulação forçada de ar, a $65{ }^{\circ} \mathrm{C}$ constante, durante 72 horas. Após este período, as amostras foram pesadas para a determinação da massa seca. Para obtenção da área foliar (AF), foi utilizado o integrador de área foliar modelo LI 3100 da Licor.

Os dados obtidos foram submetidos às análises de variância pelo teste $F$, e as médias comparadas pelo teste de Tukey a $5 \%$ de probabilidade. Os resultados obtidos em função dos níveis de salinidade foram submetidos à análise de regressão, utilizando-se o software Sisvar (FERREIRA, 2011).

\section{Resultados e Discussão}

A partir da análise de variância, verificou-se efeito significativo da interação entre os fatores salinidade e substratos, sendo observada significância para a altura de planta, área foliar, massa fresca e massa seca. Desse modo, observou-se que a resposta da cultura à salinidade é variável de acordo com o meio de cultivo, enquanto que para a variável número de folhas não houve interação dos substratos e salinidade (Tabela 2). Quando dos resultados para os fatores isolados, observou-se significância para todas a variáveis estudadas para substrato e salinidade. 
Tabela 2. Resumo da análise de variância para as características número de folhas, altura da planta, área foliar, massa fresca e seca da parte aérea de plantas de rúcula cultivar Apreciatta, aos 40 dias após o transplantio.

\begin{tabular}{ccccccc}
\hline \multirow{2}{*}{ FONTE DE VARIAÇÃO } & \multirow{2}{*}{$\mathrm{GL}$} & \multicolumn{5}{c}{$\mathrm{QM}$} \\
\cline { 3 - 7 } & & $\mathrm{NF}$ & $\mathrm{AP}$ & $\mathrm{AF}$ & $\mathrm{MFPA}$ & $\mathrm{MSPA}$ \\
\hline Substratos (I) & 2 & $6,72^{*}$ & $30,68^{* *}$ & $106231,85^{* *}$ & $1097,40^{* *}$ & $5,56^{* *}$ \\
Salinidade (II) & 4 & $15,78^{* *}$ & $175,20^{* *}$ & $553816,64^{* *}$ & $1114,17^{* *}$ & $4,87^{* *}$ \\
Interação (I x II) & 8 & $1,93 \mathrm{~ns}$ & $11,69^{* *}$ & $249505,04^{* *}$ & $91,43^{*}$ & $0,85^{*}$ \\
R. Linear & 1 & $59,03^{* *}$ & $632,88^{* *}$ & $1745880,12^{* *}$ & $3802,51^{* *}$ & $17,12^{* *}$ \\
R. Quadrática & 1 & $3,87 \mathrm{~ns}$ & $68,44^{* *}$ & $31221,98^{*}$ & $3,63 \mathrm{~ns}$ & $0,19 \mathrm{~ns}$ \\
Resíduo & 45 & 1,51 & 2,17 & 6448,24 & 38,24 & 0,36 \\
\hline CV\% & - & 12,17 & 5,99 & 24,70 & 22,85 & 19,22
\end{tabular}

${ }^{*},{ }^{* *}$-Significativos a 5 e $1 \%$ de probabilidade, respectivamente, pelo teste $\mathrm{F}$.

Observa-se aumento no número de folhas quando as plantas de rúcula foram cultivadas no SUB2 e SUB3 em comparação as plantas cultivadas no SUB1 (Figura 1A). Isso pode ser justificado pela presença de maiores teores de matéria orgânica nos SUB2 e SUB3, visto que, a utilização de matéria orgânica fornece nutrientes, melhoram as condições do solo, promovendo o aumento da porosidade e aeração (SALLES et al., 2017) e também apresentam bioatividade, ou seja, efeitos estimulantes, tais como indução de crescimento nas plantas (ZANDONADI et al., 2014).
Com o aumento da condutividade elétrica da água de irrigação houve uma redução de 5,5 folhas por planta para cada nível unitário, correspondendo a um decréscimo de $24,77 \%$, quando comparado a maior e menor condutividade elétrica da água de irrigação (Figura 1B). Essa redução do número de folhas, é uma alternativa que a plantas utilizam para reduzir a transpiração e manter os seus tecidos hidratados (YOUSIF et al., 2010).

Figura 1. Número de folhas de plantas de rúcula cultivar Apreciatta, em função dos substratos (A) e níveis de condutividade elétrica da água de irrigação (B), aos 40 dias após o transplantio.

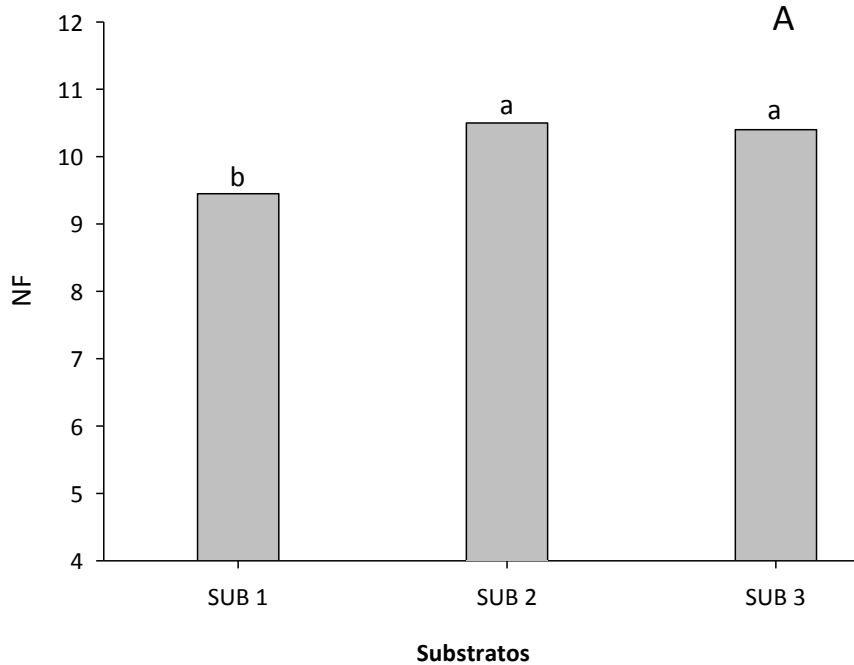

Alguns estudos sobre a tolerância da cultura da rúcula ao estresse salino têm sido desenvolvidos, observando-se efeitos negativos

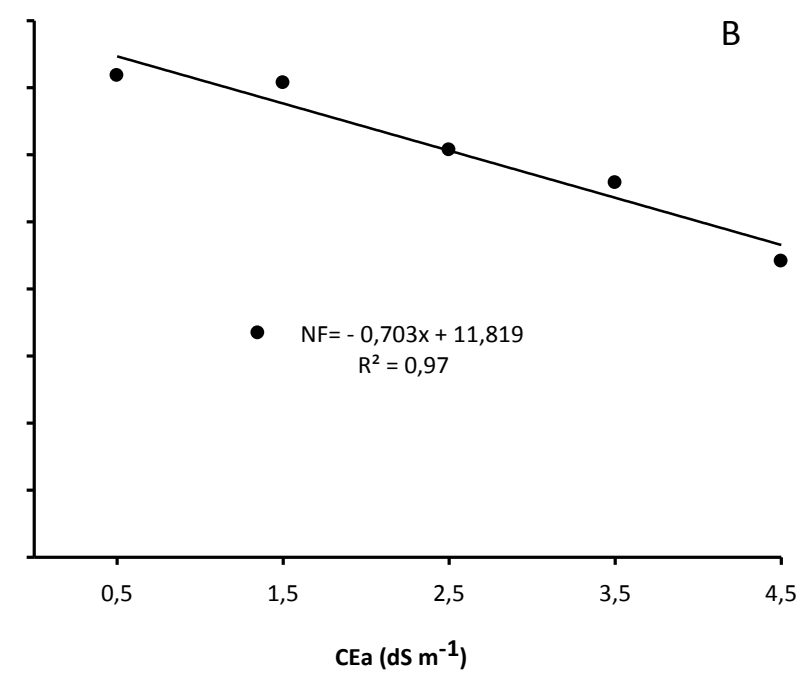

da salinidade sobre o desenvolvimento das plantas, ocasionando o fechamento estomático, a redução da transpiração e em consequência, 
redução da taxa fotossintética (SILVA et al., 2008; SILVA et al., 2011; SANTOS et al., 2012).

Para a altura de plantas, observou-se comportamento quadrático para a interação entre substratos e os níveis salinos da água. Quando comparado o maior e o menor nível de salinidade da água de irrigação, houve uma redução de 42,49, 27,75 e 27,95\% para o SUB1, SUB2 e SUB3, respectivamente (Figura 2A).

Na Figura 2B, observa-se redução da área foliar em resposta ao aumento da salinidade, obtendo-se na condutividade elétrica de 4,5 dS $\mathrm{m}^{-1} 121,177$ e $133,25 \mathrm{~cm}^{2}$, o que corresponde a uma redução de $71,36,68,94$ e $78,33 \%$ quando comparado ao menor nível de salinidade da água de irrigação $\left(0,5 \mathrm{dS} \mathrm{m}^{-1}\right)$ para os SUB1, SUB2 e SUB3, respectivamente.

A massa fresca da parte aérea foi afetada significativamente pela salinidade, tendo efeito variado de acordo com os substratos utilizados, de forma que os dados obtidos foram ajustados ao modelo linear. A partir das equações ajustadas, verificou-se que com o aumento crescente da salinidade na água de irrigação houve um decréscimo na produção de massa fresca da parte áerea para o SUB1, SUB2 e SUB3 de 4,51, 2,31 e 6,78 gramas, respectivamente para cada incremento unitário da salinidade na água de irrigação, obtendo perdas totais de $64,25,26,02$ e $60,55 \%$ quando comparado o menor com o maior nível de salinidade (Figura 2C).

Observa-se na Figura 2D, que a partir da condutividade elétrica de $1,5 \mathrm{dS} \mathrm{m}^{-1}$ houve redução na massa seca da parte aérea da planta

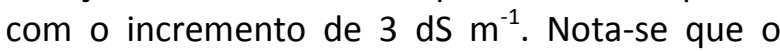
substrato composto por húmus de minhoca apresentou maiores médias de massa seca da parte aérea com aumento da salinidade na água de irrigação em comparação com os substratos SUB3 e SUB1, ocorrendo reduções de $18,41 \%$ para o SUB2, $20,30 \%$ para o substrato SUB3 e $63,10 \%$ para SUB1. 
Figura 2. Altura (A), área foliar (B), massa fresca da parte aérea (C) e massa seca da parte aérea (D) de plantas de rúculas cultivar Apreciatta, em função dos substratos e níveis de condutividade elétrica da água de irrigação aos 40 dias após o transplantio.
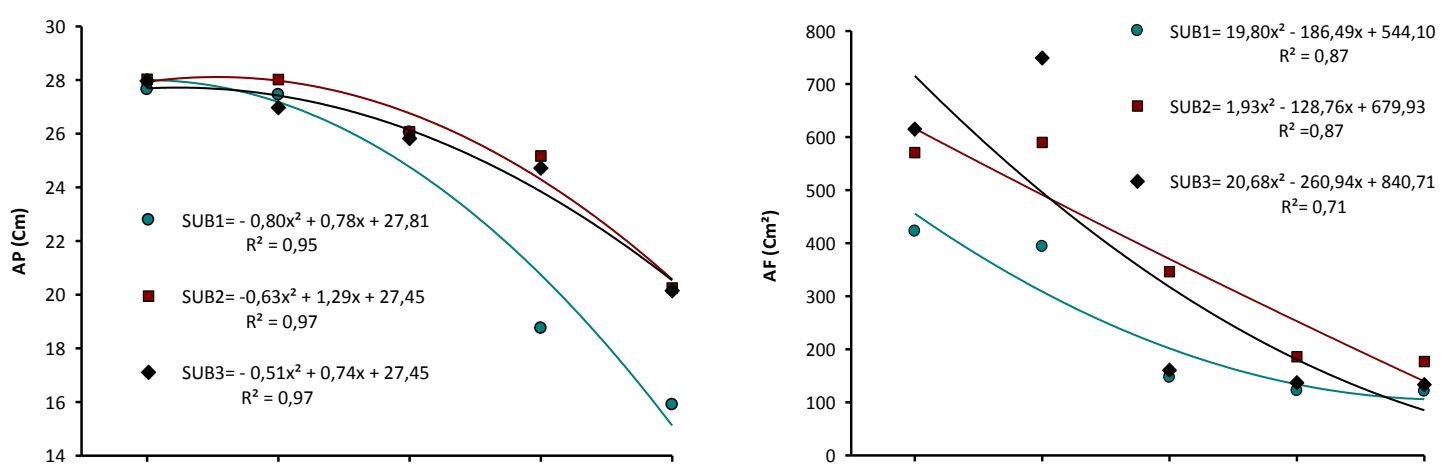

C

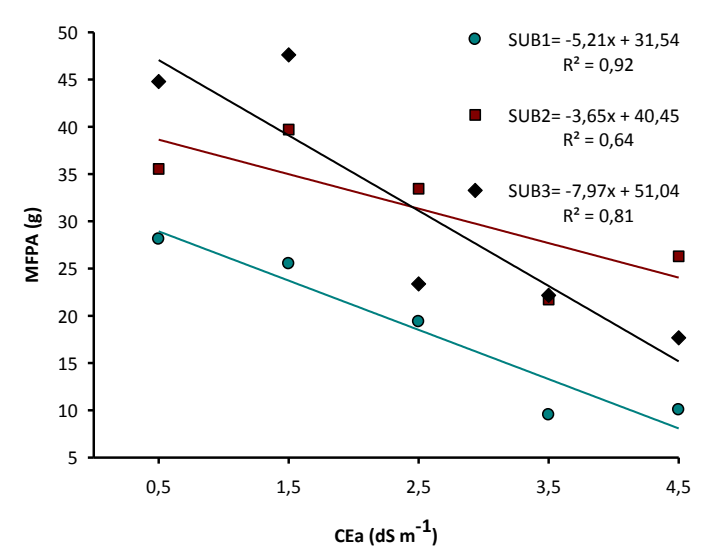

A redução na altura das plantas pode ser atribuída ao excesso de sais na solução do solo, reduzindo o potencial hídrico da água no solo, fazendo com que a planta realize o ajustamento osmótico, além de provocar alterações hormonais e nutricionais modificando as atividades metabólicas das células no processo de alongamento celular, e como consequência, o crescimento da planta (TAIZ et al., 2017).

No entanto as plantas que foram cultivadas no SUB2 e SUB3, apresentaram menores reduções na altura em comparação ao SUB1, isso pode ser justificado em virtude de que estes substratos possuem maiores teores de matéria orgânica. A incorporação de matéria orgânica ao solo promove a mineralização do carbono das diferentes fontes orgânicas mesmo em níveis elevados de salinidade, diminui a agressividade dos sais à biota do solo, estimulando a germinação e crescimento das plantas (SILVA JÚNIOR et al., 2009).
A área foliar tem sua importância por ser uma variável de crescimento indicativa da produtividade, visto que 0 processo fotossintético depende da interceptação da energia luminosa e sua conversão em energia química, sendo este um processo que ocorre diretamente na folha (TAIZ et al., 2017).

A redução da área foliar é um importante mecanismo adaptativo de plantas cultivadas sob excesso de sais e estresse hídrico, visto que, sob tais condições, é interessante a redução na transpiração e, consequentemente, diminuição do carregamento de íons de $\mathrm{Na}^{+}$e $\mathrm{Cl}^{-}$no xilema e conservação da água nos tecidos das plantas (TAIZ et al., 2017). Este decréscimo da área foliar está relacionado a um dos mecanismos de adaptação da planta ao estresse salino, diminuindo a superfície transpirante (TESTER; DAVENPORT, 2003).

Em experimento conduzido por Silva et al. (2008), observaram que com o com o aumento 
da salinidade o substrato composto por esterco bovino apresentou melhor desempenho no desenvolvimento das plantas em comparação com as demais fontes orgânicas. Desta forma, inferir-se que as fontes de adubo orgânico pode ser uma alternativa para o cultivo desta hortaliça sob condição salina.

A massa fresca das plantas é uma característica muito sensível às oscilações hídricas, uma vez que a maior parte dos vegetais é formada por água, que é um componente imprescindível para os processos vitais dos vegetais (TAIZ et al., 2017). Redução significativa na massa fresca de plantas de rúcula com o aumento da salinidade, foram observadas por (SILVA et al., 2011)

Quando se trata de espécies de ciclo curto, como a rúcula, o Húmus de minhoca realiza a disponibilização mais rápida de nutrientes para a planta (ARMOND et al., 2016). E em condições de salinidade os insumos orgânicos estimulam a redução do potencial osmótico no interior do sistema radicial, contribuindo para a absorção de água e ajustamento osmótico das plantas (FREIRE et al., 2015).

Redução significativa na massa seca em resposta à salinidade também têm sido observados para outras hortaliças folhosas, como a alface (DIAS et al., 2011; OLIVEIRA et al., 2010; SANTOS et al., 2012). Esses resultados podem ser atribuídos ao aumento da concentração de sais no substrato, que atuam negativamente no processo fisiológico, reduzindo a absorção de água pelas raízes, inibindo a atividade meristemática, o alongamento celular, redução do acúmulo de fotoassimilados e, em consequência, o crescimento e o desenvolvimento das plantas (TAIZ et al., 2017).

\section{Conclusões}

Níveis crescentes de salinidade da água de irrigação afeta de forma negativa as características de crescimento de plantas de rúcula cultivar Apreciatta, no entanto, os substratos com adição de matéria orgânica atenuaram os efeitos nocivos da salinidade, sendo uma alternativa viável para o cultivo da rúcula em condições de salinidade.

\section{Referências}

ARMOND, C.; OLIVEIRA, V. C.; GONZALEZ, S. D. P.; OLIVEIRA, F. E. R.; SILVA, R. M.; LEAL, T. T. B.; REIS, A. S.; SILVA, F. Desenvolvimento inicial de plantas de abobrinha italiana cultivada com húmus de minhoca. Horticultura Brasileira, v.34, n.3, p. 439-442, 2016.

https://doi.org/10.1590/S0102-05362016003022

DIAS, N. S.; JALES, A. G. O.; SOUSA NETO, O. N.; GONZAGA, M. I. S.; QUEIROZ, I. S. R.; PORTO, M. A. F. Uso de rejeito da dessalinização na solução nutritiva da alface, cultivada em fibra de coco. Ceres, v.58, n.5, p. 632-637, 2011.

https://doi.org/10.1590/S0034$\underline{737 X 2011000500014}$

DINIZ NETO, M. A.; SILVA, I. F.; CAVALCANTE, L. F.; DINIZ, B. L. M. T.; SILVA, J. C. A.; SILVA, E. C. Mudas de oiticica irrigadas com águas salinas no solo com biofertilizante bovino e potássio. Revista Brasileira de Engenharia Agrícola e Ambiental, v.18, n.1, p. 10-18, 2014.

https://doi.org/10.1590/S141543662014000100002

FERREIRA, D. F. Sisvar: um programa para análises e ensino de estatística. Symposium, v.6, p. 36-41, 2011.

FREIRE, J. L. O.; CAVALCANTE, L. F.; DANTAS, M. M. M.; SILVA, A. G.; HENRIQUES, J. S.; ZUZA, J. F. C. Estresse salino e uso de biofertilizantes como mitigadores dos sais nos componentes morfofisiológicos e de produção de glicófitas. Revista Principia, [S.I.], n.29, p. 29-38, 2016.

https://doi.org/10.18265/151703062015v1n29p29-38

FREIRE, J. L. O.; CAVALCANTE, L. F.; DIAS, T. J.; DANTAS, M. M. M.; MACEDO, L. P. M.; AZEVEDO, T. A. O. Teores de micronutrientes no solo e no tecido foliar do maracujazeiro amarelo sob uso de atenuantes do estresse salino. Agropecuária Técnica, v.35, n.1, p. 65-81, 2015.

GERVÁSIO, E. S.; CARVALHO, J. A.; SANTANA, M. J. Efeito da salinidade da água de irrigação na produção da alface americana. Revista Brasileira de Engenharia Agrícola e Ambiental, v.4, n.1, p. 125-128, 2000. https://doi.org/10.1590/S1415$\underline{43662000000100023}$

GRANGEIRO, L. C.; OLIVEIRA, F.; NEGREIROS, M.; MARROCOS, S.; LUCENA, R.; OLIVEIRA, R. Crescimento e acúmulo de nutrientes em coentro e rúcula. Revista Brasileira de Ciências Agrárias, v.6, n.1, p. 11-16, 2011.

https://doi.org/10.5039/agraria.v6i1a634 
HASANUZZAMAN, M.; ALAM, M. M.; RAHMAN, A.; HASANUZZAMAN, M.; NAHAR, K.; FUJITA, M. Exogenous proline and glycine betaine mediated upregulation of antioxidant defense and glyoxalase systems provides better protection against saltinduced oxidative stress in two rice (Oryza sativa L.) varieties. BioMed Research Internatinal, v.1, p. 1-17, 2014.

https://doi.org/10.1155/2014/757219

JAMES, R. A.; BLAKE, C.; ZWART, A. B.; HARE, C. R. A.; RATHJEN, A. J.; MUNNS, R. Impact of ancestral wheat sodium exclusion genes Nax1 and Nax2 on grain yield of durum wheat on saline soils. Functional Plant Biology, v.39, p. 609-618, 2012. https://doi.org/10.1071/FP12121

MEDEIROS, J. F.; SILVA, M. C. C.; SARMENTO, D. H. A.; BARROS, A. D. Crescimento do meloeiro cultivado sob diferentes níveis de salinidade, com e sem cobertura do solo. Revista Brasileira de Engenharia Agrícola e Ambiental, v.11, n.3, p. 248-255, 2007. https://doi.org/10.1590/S141543662007000300002

MUNNS, R.; GILLIHAM, M. Salinity tolerance of crops-what is the cost? New Phytologist, v.208, n.3, p. 668-673, 2015.

https://doi.org/10.1111/nph.13519

NASCIMENTO, I. B.; MEDEIROS, J. F.; ALVES, S. S. V.; LIMA, B. L. C.; SILVA, J. L. A. Desenvolvimento inicial da cultura do pimentão influenciado pela salinidade da água de irrigação em dois tipos de solos. Agropecuária Científica no Semiárido, v. 11, n. 1, p. 37-43, 2015.

OLIVEIRA, E. Q.; SOUZA, R. J.; CRUZ, M. C. M.; MARQUES, V. B.; FRANÇA, A. C. Produtividade de alface e rúcula, em sistema consorciado, sob adubação orgânica e mineral. Horticultura Brasileira, v.28, n.1, p. 36-40, 2010.

https://doi.org/10.1590/S0102-

$\underline{05362010000100007}$

OLIVEIRA, F. A; OLIVEIRA, M. K. T.; NETA, M. L. S.; SILVA, R. T.; SOUZA, A. A. T.; SILVA, O. M. P.; GUIMARÃES, I. P. Desempenho de cultivares de rúcula sob diferentes níveis de salinidade da água de irrigação. Agropecuária científica no semiárido, v.8, n.3, p. 67-73, 2012.
PLAŻEK, A., TATRZAŃSKA, M., MACIEJEWSKI, M., KOŚCIELNIAK, J., GONDEK, K., BOJARCZUK, J., DUBERT, F. Investigation of the salt tolerance of new polish bread and durum wheat cultivars. Acta Physiologiae Plantarum, v.35, n.8, p. 25132523, 2013. https://doi.org/10.1007/s11738-0131287-9

SALLES, J. S.; STEINER, F.; ABAKER, J. E. P.; FERREIRA, T. S.; MARTINS, G. L. M. Resposta da rúcula à adubação orgânica com diferentes compostos orgânicos. Revista de Agricultura Neotropical, v.4, n.2, p. 35-40, 2017.

https://doi.org/10.32404/rean.v4i2.1450

SANTOS, R. S. S.; DIAS, N. S.; DUARTE, S. N.; LIMA, C. J. G. S. Uso de águas salobras na produção de rúcula cultivada em substrato de fibra de coco. Revista Caatinga, v.25, p. 113-118, 2012.

SANTOS, R. S. S.; DIAS, N. S.; DUARTE, S. N.; LIMA, C. J. G. S.; FERNANDES, C. S., MIRANDA, J. H. Cultivo da rúcula em substrato de fibra de coco sob solução nutritiva salina. Revista Cultura Agronômica, v.27, n.1, p. 12-21, 2018.

SILVA JÚNIOR, J. M. T.; TAVARES, R. C.; MENDES FILHO, P. F.; GOMES, V. F. F. Efeitos de níveis de salinidade sobre a atividade microbiana de um Argissolo Amarelo incubado com diferentes adubos orgânicos. Revista Brasileira de Ciências Agrárias, v.4, n.4, p. 378-382, 2009.

https://doi.org/10.5039/agraria.v4i4a1

SILVA, A. O.; SILVA, D. J. R.; SOARES, T. M.; SANTOS A. N.; ROLIM, M. M. Produção de rúcula em sistema hidropônico NFT de água salina da semiárido - PE e rejeito de dessalinizador. Revista Brasileira de Ciências Agrárias, v.6, n.1, p. 147155, 2011.

https://doi.org/10.5039/agraria.v6i1a929

SILVA, F. V.; DUARTE, S. N.; LIMA, C. J. G. S.; DIAS, N. S.; SANTOS, R. S. S.; MEDEIROS, R. F. Cultivo hidropônico de rúcula utilizando solução nutritiva salina. Revista Brasileira de Ciências Agrárias, v.8, n.3, p. 476-482, 2013.

https://doi.org/10.5039/agraria.v8i3a1689

SILVA, J. K. M.; OLIVEIRA, F. A.; MARACAJÁ. P. B. FREITAS, R. S.; MESQUITA, L. X. Efeito da salinidade $\mathrm{e}$ adubos orgânicos no desenvolvimento da rúcula. Revista Caatinga, v.21, n.5, p. 30-35, 2008. 
SOUZA, J. L.; MOURA FILHO, G.; LYRA, R. F. F.; TEODORO, I.; SANTOS, E. A.; SILVA, J. L.; SILVA, P. R. T.; CARDIM, A. H.; AMORIM, E. C. Análise da precipitação pluvial e temperatura do ar na região do Tabuleiro Costeiro de Maceió, AL, período 1972-2001. Revista Brasileira de Agrometeorologia, v.12, n.1, p. 131-141, 2004.

TAIZ, L.; ZEIGER, E.; MOLLER, I. M.; MURPHY, A. Fisiologia e desenvolvimento vegetal. 6 . ed. Porto Alegre: Artmed, 2017. 858 p.

TESTER, M.; DAVENPORT, R. $\mathrm{Na}^{+}$tolerance and $\mathrm{Na}^{+}$transport in higher plants. Annals of Botany, v.91, n.5, p. 503-527, 2003.

https://doi.org/10.1093/aob/mcg058

TRANI, P. E.; PURQUERIO, L. F. V.; FIGUEIREDO, G. J. B.; TIVELLI, S. W.; BLAT, S. F. Calagem e adubação da alface, almeirão, agrião d'água, chicória, coentro, espinafre e rúcula. Campinas: IAC, 2014. 16 p. (IAC. Informações tecnológicas, 97).

YOUSIF, B. S.; NGUYEN, T. N.; FUKUDA, Y., HAKATA, H., OKAMOTO, Y.; MASAOKA, Y.; SANEOKA, $\mathrm{H}$. Effect of salinity on growth, mineral composition, photosynthesis and water relatíons of two vegetable crops; New Zealand spinach (Tetragonia tetragonioides) and water spinach (Ipomoea aquatica), International Journal of Agriculture and Biology, v.12, p. 211-216, 2010.

ZANDONADI, D. B; SANTOS M. P; MEDICI L. O; SILVA J. Ação da matéria orgânica e suas frações sobre a fisiologia de hortaliças. Horticultura Brasileira, v.32, n.1, p. 14-20, 2014.

https://doi.org/10.1590/S0102$\underline{05362014000100003}$ 